\title{
Virus-Based Vectors: A New Approach for the Production of Recombinant Proteins
}

\author{
Zahid Naseri', Ghaffar Khezri', Seyed Javad Davarpanah ${ }^{2 *}$, Hamideh Ofoghi ${ }^{3}$ \\ ${ }^{1}$ Department of Plant Breeding and Biotechnology, Faculty of Agriculture, University of Tabriz, Iran \\ ${ }^{2}$ Applied Biotechnology Research Center, Baqiyatallah University of Medical Sciences, Tehran, Iran \\ ${ }^{3}$ Department of Biotechnology, Iranian Research Organization for Science and Technology, Tehran, Iran
}

Corresponding Author: Seyed Javad Davarpanah, Applied Biotechnology Research Center, Baqiyatallah University of Medical Sciences, Tehran, Iran. Tel: +98-9380755272, Email: davarpanah@bmsu.ac.ir

Received October 12, 2018; Accepted January 13, 2019; Online Published March 15, 2019

\begin{abstract}
Recombinant proteins have become one of the basic human needs today for pharmaceutical, industrial and research purposes. The conventional methods of producing recombinant proteins, including bacterial systems, yeast, and human cells, have led to rising prices and biosafety problems for these products. Research on commercial production of recombinant proteins prompted a new method based on plant RNA viruses and plant hosts, which is known as transient expression system. Accordingly, a viral vector based on the plant RNA virus genome was designed in which the target gene is placed underneath a viral subgenomic promoter. In these vectors, despite the genetic manipulation, the ability to infect the entire plant that was present in the virus was preserved and, several days after plant infestation, it became bioreactor for the production of recombinant protein. The advances made in this field led to the creation of hybrid vectors based on plant viruses and Agrobacterium T-DNA (Transfer DNA). The amount of recombinant protein produced by these vectors was up to $5 \mathrm{~g} / \mathrm{kg}$ of fresh weight, which is considered a reliable record. The abundant benefits of this method have attracted the attention of researchers. Some of the benefits include: the rapid and high production rate, reduced production costs and the bio-safety of the manufactured products. Several recombinant drugs are currently produced by the transient expression system, either delivered to the consumer or by clinical trials. This review presents how to discover, creation and development of viral vectors in transient expression systems in order to produce recombinant proteins.

Keywords: Transient Expression, Viral Vectors, Recombinant Protein

Citation: Naseri Z, Khezri G, Davarpanah SJ, Ofoghi H. Virus-based vectors: a new approach for the production of recombinant proteins. J Appl Biotechnol Rep. 2019;6(1):6-14. doi:10.29252/JABR.06.01.02.
\end{abstract}

\section{Introduction}

The recombinant protein is a protein that its coding gene is expressed in a heterologous host. Low-level production of a protein of interest by its natural resources and gene owner organism is the reason for its production in a heterologous host. The first pharmaceutical recombinant protein was human insulin that was approved for human use by regulatory organizations in $1982 .{ }^{1}$ Pharmaceutical proteins are very powerful drugs with no side effects, requiring less production time compared to small molecule drugs. ${ }^{2}$ Recombinant proteins are being expressed in different expression systems including bacteria, yeast, plants, and mammalian cells. ${ }^{2,3} \mathrm{Never}$ the less, plants are the most economic producers requiring the least light, water, $\mathrm{Co}_{2}$ and minerals. ${ }^{4}$ Low production cost and safety of products due to the lack of common pathogens between plants and animals are the advantages of recombinant protein production by plants. ${ }^{3,5}$ In addition, plants possessing machinery and constituents to modify eukaryotic proteins allowing targeting subcellular compartments, correct folding and post-translational modifications. ${ }^{6}$ Also, studies during the past 20 years have proved that a broad spectrum of valuable proteins such as human growth hormone, antibodies, vaccines, industrial enzymes, biopolymers, and other bioproducts have been efficiently expressed in plants. ${ }^{7-14}$

Recombinant proteins are produced in plants via stable transformation (nucleus or plastid transformation) or transient expression system. ${ }^{3,5,8-11,15,16}$ The generation of permanent transgenic plants and protein production requires more time and considerable expenses while the expression level of protein of interest is relatively low. ${ }^{17}$ Agrobacteriummediated stable transformation requires binary vectors which can be manipulated in both Escherichia coli and Agrobacterium. These vectors carry a selectable marker for transgenic plant regeneration, ${ }^{18}$ whereas in transient expression using virusbased vectors selectable markers are not required. ${ }^{19}$ The elimination of the selection gene reduces the size of the vector and leads to easier vector manipulation, including reducing the probability of having the same restriction site on the vector and increasing the ligation of the restricted vector and increasing the amount of transformation of the bacteria. ${ }^{20}$ Regarding the above, transient expression using virus-based vectors is an alternative approach to produce an affordable

Copyright (C) 2019 The Author(s). This is an open-access article distributed under the terms of the Creative Commons Attribution License (http:// creativecommons.org/licenses/by/4.0), which permits unrestricted use, distribution, and reproduction in any medium, provided the original work is properly cited. 
amount of recombinant protein $(1-2 \mathrm{~g} / \mathrm{kg}$ plant biomass $){ }^{3}$

\section{Basics of Transient Expression}

Agrobacterium tumefaciens is the main tool for the generation of transgenic plants. ${ }^{18}$ During the plants and bacteria coculture, single chain T-DNA (Transfer DNA) is transferred from bacteria to plant cells. ${ }^{21}$ As soon as the T-DNA is inserted into the plant cell, this single chain DNA changes to a double strand DNA and migrates into the nucleus. Only a few percents of these double-stranded DNAs are inserted in the chromosomes of the host cell and make the transformed cell resulting in transgenic plants. Although the long-term destiny of non-inserted single chain T-DNA is not obvious, they are transcribed for a period and this is the base of A. tumefaciens mediated transient expression system (Figure 1). ${ }^{1922}$ The production of recombinant proteins using transient expression especially based on RNA viral vectors has gained a high level of popularity due to simple and easy engineering, high level of production of the protein of interest, scalability, higher safety, lower costs and lack of heritability to next generation. ${ }^{4,23,24}$ Usually, Tobacco Mosaic Virus (TMV), cowpea mosaic virus $(\mathrm{CMV})$, potato virus $\mathrm{X}$ (PVX) or tobacco rattle virus (TRV) genome sequences which are small (+) RNA strands are used to construct these vectors which have been developed and are used for commercial production of heterologous proteins. ${ }^{25}$ The vectors are transferred into recipient plant cells via infiltration of Agrobacterium suspension carrying a T-DNA harboring the virus sequence. ${ }^{25-27}$

\section{Virus-Based Vectors}

Viruses are able to do various activities such as host infection, replication of nucleic acids, protein translation, assembling of

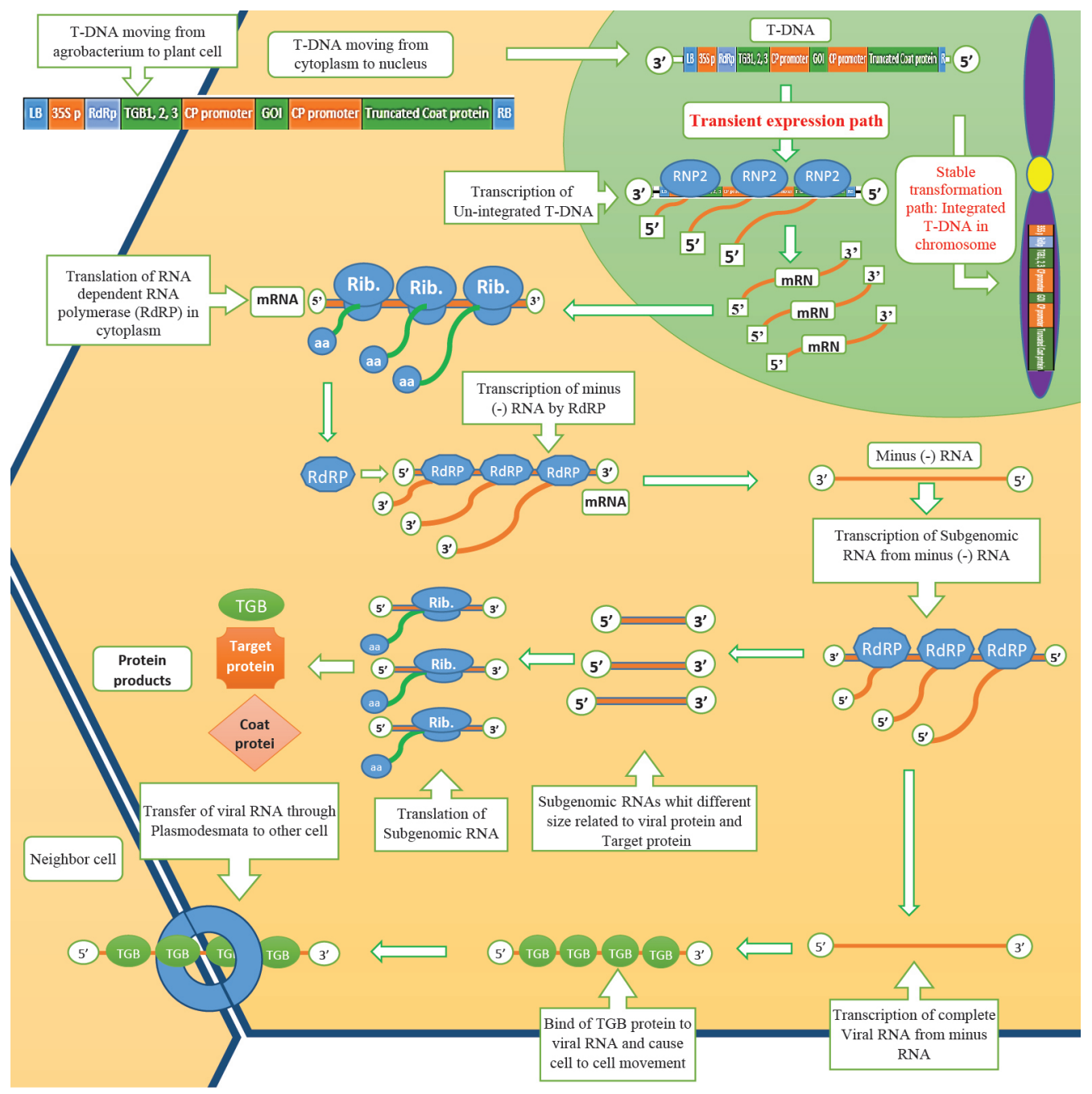

Figure 1. Transient expression path in viral vector mediate Agrobacterium. After the entrance of single strand T-DNA to cell cytoplasm, the T-DNA moving to nucleus continuous. In the nucleus, two events may occur. The possible first event is the integration of T-DNA into one of the chromosomes that is known as a stable transformation path. The second possible event happens when the T-DNA does not integrate into chromosomes. The un-integrated T-DNA act as transcriptional units and transcription of this type of T-DNA is the start of the transient expression path. After transcription, the mRNA is obtained which is similar to viral RNA. The first Translation product of this mRNA is the RNA dependent RNA polymerase which is briefly known as RdRP. As soon as the RdRP is produced, this enzyme starts to transcript the mRNA which is produced from T-DNA and leads to the production of 3' to 5' minus (-) RNA. After the creation of minus RNA, RdRP starts to transcript from 3' to 5' minus RNA and leads to the production of $5^{\prime}$ to $3^{\prime}$ subgenomic RNAs and $5^{\prime}$ to $3^{\prime}$ complete viral RNA. Each subgenomic RNA is the translational units that are translated by the host ribosome and lead to the production of proteins. One of the produced proteins is the target protein that through genetic engineering, its DNA sequencing was added to the end of the subgenomic CP promoter. Other proteins include the TGB proteins in the PVX vector or the movement protein in the TMV vector and truncated coat protein in both vectors. The TGB proteins and movement protein binds to viral RNA and play a key role in the cell to cell movement of viral RNA from plasmodesmata. 
mature virions, cell to cell dispersion, spreading to distal parts of infections, affect biosynthetic pathways like silencing many cell functions and etc. ${ }^{28}$ The ability of plant viruses to force infected cells to produce encoded proteins by virus genome has reinforced the hypothesis that plant viruses can be used as vectors for heterologous protein expression in plants. ${ }^{29}$ The first in vivo and in vitro expression of viral RNA in 1984 was a turning point for the application of virus-based vectors which directed scientists to the invention of plant virus-based vectors for the production of recombinant proteins in plants. These vectors are not inserted in the host genome and have a high potential for expression because they can easily move from one plant cell to another one. ${ }^{30}$ The expression of an epitope of a polio antigen on the capsid protein of TMV in 1986 supports the above hypothesis. ${ }^{29}$

\section{First Generation Virus-Based Vectors: Full Virus Strategy} The first generation of virus-based vectors are the viruses that express the gene of interest in addition to their own natural genes. In this process, the gene of interest is expressed by a promoter/strong viral promoter like subgenomic of capsid promoter which has been doubled by genetic engineering in addition of its presence in virus genome, or by fusion to a coding sequence of capsid protein as a fusion protein that can be used for expression of immunogenic epitopes. ${ }^{31}$ The gene of interest is sent to plant cells as a transcript of infecting DNA or preferably as mature virus particles. This can be performed by spraying a suspension of virus particles and corrosive materials such as carborundum on the crops in the field; this is named "sfull virus strategy". ${ }^{3}$ Depending on vector efficacy and the ability for systemic movement, 2 to 3 weeks is required for the infection of the whole body of transfected plants. The spray of Agrobacterium was introduced as an alternative method to transfer a copy of T-DNA to plants by the PVX-based vector. The host plants were transformed by the virus suppressor factor. Even though this approach provided a fast and easy method, but produced a very low level of recombinant protein (0.04-0.3 total soluble protein [TSP]) requiring more advances and optimization for acceptable production. $^{32}$

Many efforts to produce recombinant proteins using first generation virus-based vectors revealed the positive and negative points of this strategy. The positive points were that many papers had reported the successful expression of the immunogenic epitopes which were fused with capsid proteins of the virus. Additionally, the immunization of the produced epitopes showed a special degree of protection in animal models. The negative points were that several research groups had concentrated on the production of the L1 capsid protein of papillomavirus (human and cottontail papillomavirus) in plants and as a result had observed problems with the assembly of virus particles in the plant cells. Aso, the product quantity of virus-based vectors was lower than stable transgenic plants. ${ }^{33,34}$ Researchers believe that the low production rate of L1 protein is due to the quick destruction of the L1 gene because of its large size $(1.5 \mathrm{~kb})$, thereby researches begin looking for more evidence. The obligatory limitations of "full virus" vectors for insert size in PVX-based vector revealed the negative correlation between the insert size and the stability of the vector. ${ }^{35}$ The industrial development of this strategy requires transfection of a huge number of plants; and their leaves and tissues in a greenhouse or on the field.The "full virus" strategy using first-generation vectors with systemic ability to propagate was proposed for whole plant transfection, although the limitations of this method were quite clear. Systemic vector never contaminated all the harvested parts of the plant (for example lower leaves); the spread of the virus, called the rate of infection from leaf to the other, was inconsistent and with different velocity, and the vector was usually unstable, which is the reason despite the infection of many tissues, no protein expression occurred. ${ }^{3}$

The Second Generation of Virus-Based Vectors: Deconstructed Viruses

Limitations of the first generation vectors made scientists to redesign these vectors, using deconstructed virus genome instead of the whole genome of the virus. Additional studies resulted in the removal of unnecessary and keeping required parts of the vectors for essential functions which promoted the first generation vectors to the second generation of virusbased vectors. ${ }^{37-39}$ In this method, the only required fragments of the viral genome for effective expression of the target gene remained in the vector structure and the other required functions were provided out of the virus system by non-viral derived sequences of the vector. ${ }^{36}$ The functions that were provided out of the viral system included molecular system infections, multiplication, cell-cell movement, assembly of the virus particles, silencer of the plant cell synthesis system, silencing suppressors, systemic disperser and etc. On the contrary, the replication of viral genom in host cell is a strong and species-independent property which is considered as a process reinforcement in most functions which should be kept in viral vectors.

Some of the viral systems in the first generation viral vector were deficient. For example, the virus is not able to infect the host cell without physical or biological (insect) injuries which are not desirable from a biosafety point of view. In addition, systemic movement of the virus is very tissue and speciesspecific, which is easily damaged by genetic manipulation. ${ }^{37}$ Due to the allocation of a high amount of metabolic resources to the high expression level of the capsid protein, which is needed for the systemic movement, the expression of protein of interest reduced. An alternative was to remove capsid protein genes and replacesystemic movement ability by Agrobacterium and its Transfer DNA. The T-DNA is a part of the tumor-inducing plasmid (Ti) of Agrobacterium, used by the bacterium for the transformation of host plant and also to produce specific amino acids (octopine, nopaline) for nutrition. The T-DNA as a single strand DNA integrate to host genome and leads to the expression of harboring bacterial usable amino acid genes. In fact, Agrobacterium is the first genetic engineer in the nature. ${ }^{40}$ It was shown in 1993 that TMV-based vector transfer using Agrobacterium is very deficient with one transfection per $10^{8}$ Agrobacterium which is 
related to the low ability of primary transcripts for leaving the nucleus; which as a result is a bottleneck for active replicon formation. ${ }^{27}$ The RNA of viruses with cytoplasmic RNA like TMV normally do not enter the plant cell nucleus, which is the reason why their evolution is not through nucleolar RNA editing. Study the viral genome revealed that the identification of many parts of virus genome as natural coding sequences in host plants seems to be impossible; therefore, a vector that is a simple copy of a wild virus most probably will be destroyed before reaching the cytosol. ${ }^{38}$ Thereupon, using vector modification including the insertion of silent mutations to remove modification sites, codon optimization, and the addition of plant introns; a very active synthetic T-DNA template harboring required viral segment is synthesized. Transferring this DNA template to plant cell resulted in the processing of DNA information as an active replicon in almost all cells (>93\%) which is $10^{3}$ times higher than nonmodified vector and $10^{7}$ times better than non-optimized DNA template; resulting in transfection per 10-20 infiltrated Agrobacterium. The infiltration has been performed in other plant species including pumpkin, spinach, sunflower, and red beetroot but it was more efficient in Nicotiana benthamiana. ${ }^{27}$ The second generation vectors prevent the production of infectious virus particles and as a result the plant does not spread acute infection symptoms; helping heterologous protein production. Also, these vectors produce more protein than the first generation; reaching up to $50 \%$ of TSP or 5 -gram protein per kilogram of plant biomass during 4-15 days. In addition, genes larger than 2-3 kb or proteins with molecular weight higher than $80 \mathrm{kD}$ could be expressed using these vectors due to lack of gene of capsid protein. ${ }^{41,42}$ Nowadays, the most applicable second generation vectors among the transient expression systems are those derived from Agrobacterium T-DNA combination with essential viral elements which is based on Agrobacterium mediation and viral expression system which means Agrobacterium facilitate transfer of gene construct to the cell by the transfer of T-DNA (Agroinfection). After the transfer of T-DNA into the cell, the viral elements are expressed. As a result, their assembly results in virus activation and replication is followed by a high expression of the gene of interest. Actually, magnICON ${ }^{\circledR}$ is one of the most well-known vectors of the second generation type which has been commercially used and was designed and constructed by Icon Genetics, Germany. Since several years ago, the virusbased vector which has been considered as an efficient system could overcome limitations of plants for the production of recombinant proteins which have been vastly used for the production of pharmaceutical proteins and also as research tools for functional genomic studies through gene silencing and lowering the specific plant transcripts. ${ }^{43}$ Plant RNA virusderived vectors are the most advanced ones which have been used for the production of vaccines and pharmaceutical proteins. Amongst them, TMV, CMV and PVX based vectors are viral expression vectors which have been successfully used for the production of recombinant proteins and vaccines. The TMV-based vectors have the most common application for the production of recombinant proteins. ${ }^{42}$ The positive-sense single-stranded RNA viruses (or (+)ssRNA virus) function similar to mRNA in the cytoplasm; ribosomes bind them and encode proteins based on their sequences. Regarding the high multiplication rate of viruses in the cell, exploiting the subgenomic RNA system and polycistronic RNA by plant viruses, the high number of viral strands make cells to serve virus for expression of their proteins. Geminivirus (single strand DNA viruses) vectors are DNA virus-based vectors which have been recently optimized as multifunctional vectors. ${ }^{43,44}$ Generally, the application of virus-based vectors as the basis of transient expression systems enjoy considerable advantages such as speed up of product expression, the decrease of research and development expenses, high expression, flexibility and scalability which are suitable alternatives for protein production instead of permanent expression systems (nucleus and chloroplast). ${ }^{37}$ The comparison of the structure and the functional differences between the first and second generation viral vectors is presented in Figure 2 and Table 1.

\section{Agroinfiltration of Virus-Based Vectors}

Agroinfiltration is a technique to study plant-pathogen interaction but nowadays is adopted for transient expression studies. ${ }^{45}$ In this method, Agrobacterium containing recombinant vector (viral vector) enter the intercellular spaces of the leaves through stomata or wounding the abaxial face of leaves. Infiltration of the whole plant or detached leaves is performed in different ways; the simplest one is shoot infiltration in a bacterial suspension followed by a weak vacuum (approximately 0.8-0.9 Bar) for 10-30 seconds. ${ }^{27,41,46}$ Another way to infiltrate is the injection of Agrobacterium

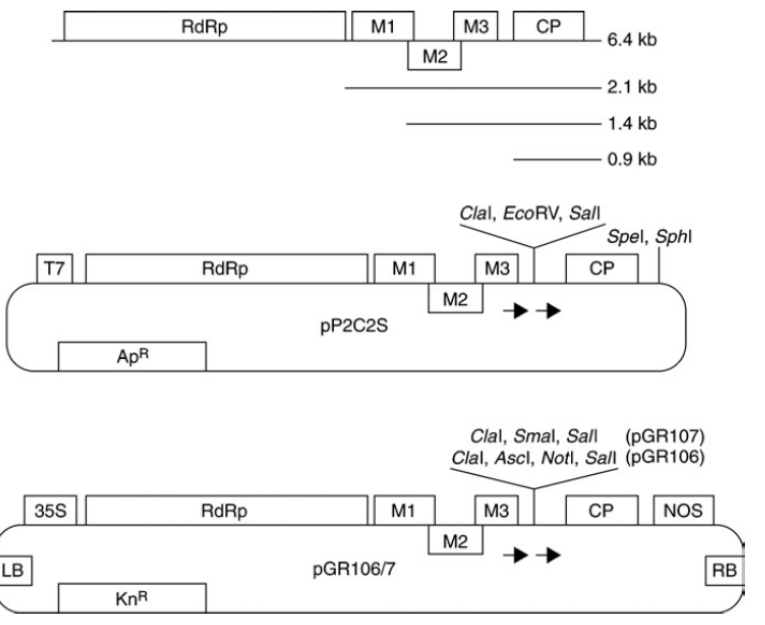

Figure 2. Schematic Representations of PVX (Potato Virus X) and PVX-Based First and Second Generation Vectors. Genome organization of wild-type PVX (A). The five major ORFs in the 6.4-kb genome are indicated by boxes. The subgenomic mRNAs from which the $5^{\prime}$ distal ORFs are expressed are indicated by lines below, with the sizes of the mRNAs. Organizations of first generation viral vector $\mathrm{PP} 2 \mathrm{C} 2 \mathrm{~S}(\mathrm{~B})$ and second generation viral vector pGR106/7 (C). The positions of the duplicated, subgenomic promoter sequences are indicated by arrows. The restriction enzyme sites in the multiple cloning sites are listed above. Features shown are: viral RNA-dependent RNA polymerase gene (RdRp); viral movement protein genes (M1, M2, M3); viral coat protein gene (CP); T7 bacteriophage (T7) and cauliflower mosaic virus $35 \mathrm{~S}$ (35S) promoters; nopaline synthase transcriptional terminator (NOS); T-DNA left and right borders (LB, $\mathrm{RB})$; $\beta$-lactamase gene (ApR) conferring ampicillin resistance; and neomycin phosphotransferase II gene $(\mathrm{KnR})$ conferring kanamycin resistance. 
Table 1. Difference Between First and Second Generation of Viral Vectors

\begin{tabular}{lcc}
\hline & First Generation & Second Generation \\
\hline Need for in vitro assembling virus & Yes & No \\
Infection by injury or insect & Yes & No \\
Production of target protein as hybrid by viral coat protein & Yes & No \\
Need for three construct & No & Yes \\
High capacity for expression of largest gene & Yes & Yes \\
High biosafety & No \\
Agrobacterium base & Low amount \\
\hline High amount production & Up to 5 g/kg \\
\hline
\end{tabular}

suspension by putting a needle-less syringe on the leaves with a little pressure, thereby, the suspension enters the empty spaces within the leaves. Vaccum infiltration is mainly applied in research laboratories to increase Agrobacterium infiltration for protein production. In vacuum infiltration, plant tissue including leaf disk or whole plant body is submerged in Agrobacterium suspension followed by a decrease-increase of pressure resulting in infection of all parts of the tissue. This method is very suitable for the production of high amounts of proteins in plant species such as lettuce and Arabidopsis which cannot be infiltrated by syringe. ${ }^{45}$ In this method, the infiltration of Agrobacterium replaces the normal functions of the virus including primary infection and systemic movement. Intracellular multiplication and cell to cell movement are performed by viral replicon. Based on the vector, host organism and final concentration of the bacteria takes 4-10 days to be completed. Depending on the gene of the interest, expression of the recombinant protein can be attained up to 5 gram per kilograms of leaf biomass. On the other hand, it will consist of more than $50 \%$ of TSP. ${ }^{3}$ Agroinfiltration is a combination of advantages of three biological systems including speed, high expression level and proper function of the virus, the efficacy of systemic transfer of plant virus-based vectors to plant cell by Agrobacterium and post-translational modifications and low production expenses in plants. Infiltrated plants are incubated in optimum conditions for 4-6 days. Afterwards, downstream processes including leaf homogenization (4-6 days post infiltration), purification, dialysis to remove salts, concentrating and confirming protein efficiency by western blotting or other tests are performed. ${ }^{45}$ In this regard, agroinfiltration can quickly assess the activity of a gene construct and speed up analysis of efficiency by the fast production of a protein of interest. This period of recombinant protein production is very suitable compared to the permanent transgenic plants which usually take 6 months. This technique is also very flexible. Actually, with the simultaneous expression of several genes it is a much more reliable indicator for the study of efficiency because the local effects which are usually seen in permanent transgenic plants are not seen in this system. ${ }^{47}$ Plant species, developmental stage and physiological status of plant play a crucial role in agroinfiltration for the amount of produced protein. ${ }^{48}$ Agroinfection is more efficient than infectious DNA and RNA molecules, especially in regards to the RNA viruses agroinfection, which is a very cheaper replacement compared to the in vitro method for changing viral DNA to RNA. It is more than a decade that agroinfection is used in transient expression systems for high-level expression of the gene of interest in mature plant leaves, and due to its lower expenses has found a wide commercial application. ${ }^{42}$ Transient expression by virus-based vectors in plants using Agrobacterium containing heterologous genes occurs in 2 to 7 days. Companies such as MEDICAGO exploit this process for the commercial large-scale production of recombinant proteins. $^{49}$

\section{Factors Affecting the Expression of Heterologous Genes in Virus-Based Vectors}

The first and the most important factor in the expression of the heterologous gene is the type of virus that the vector is designed onbecause the amount of expression varies based on the DNA or RNA of the virus. ${ }^{42}$ Codon usage of the heterologous gene is another important factor in protein expression. It can be attained experimentally but generally in applying the codon usage modifications in Nicotiana benthamiana the GC content should be over $50 \%$ in order for the heterologous protein expression to be increased. Moreover, each virus-based vector requires a special strain of Agrobacterium for infiltration and the selection of Agrobacterium depends on the $\mathrm{T}_{\mathrm{i}}$ plasmid. ${ }^{50}$ Plants respond to viral infection by post-transcriptional gene silencing defense mechanism and do not permit virus gene to be expressed. Therefore, virus-based vector requires overcoming the defense mechanism for inhibiting the gene silencing to be able to express its protein. In this regard, the inhibitors of gene silencing are exploited. Among the inhibitors suppressing post-transcriptional gene silencing novel RNA silencing suppressor, the suppressor protein for silencer of Ttomato spotted wilt RNA virus, and P19 protein (suppressor protein for silencer of tomato bushy stunt RNA virus) can be mentioned. Expression of suppressor protein along with heterologous protein increases protein expression up 50 times. $^{50,51}$

Example of Recombinant Proteins Produced by Transient Expression System

Nowadays, transient expression is used for the production of completely applicable proteins such as human growth hormone which produces hormone and was bioactive and in a high amount $(1 \mathrm{mg} / \mathrm{g}) .^{52} \mathrm{In}$ another research, two plague antigens $\mathrm{F} 1$ and $\mathrm{V}$ have expressed fusion $\mathrm{F} 1-\mathrm{V}$ protein in 2-3 $\mathrm{mg} / \mathrm{g}$ of fresh leaf weigh. In addition, it was shown that plantproduced antigens offer a high level of protection against aerobic plague bacteria in animal models. ${ }^{53}$ Another research team could express tuberculosis Ag85B antigen up to $0.8 \mathrm{mg} / \mathrm{g}$ 
of fresh leaves. ${ }^{54}$ More than 50 proteins with different origins and complexities representing all classes of pharmaceutical proteins have been expressed successfully by magnifection. ${ }^{46}$ To mention other applications of virus-based vectors for transient application the following can be pointed out: the production of AIDS vaccine (TMV-based viral vector), ${ }^{55,56}$ the production of human papiloma virus antigen (TMVbased viral vector), ${ }^{34,56}$ the production of dengue fever vaccine (TMV-based viral vector), ${ }^{56,57}$ anticancer antibodies (TMV and PVX-based viral vectors), ${ }^{56,58,59}$ Hepatitis B vaccine (TMV and PVX-based viral vectors $)^{56,60}$ and influenza vaccine. ${ }^{61}$ The MEDICAGO company has optimized agroinfiltration for the production of flu vaccine ${ }^{62}$ and the Kentucky company has established an automatic bioprocessing system that infiltrates plants in a kilogram per hour scale. ${ }^{62}$ Results reveal that agroinfection is the most suitable method for the application of PVX-based viral vectors for the production of recombinant proteins. ${ }^{63}$ The most recent reports of the status of pharmaceutical proteins produced in plants to prevent epidemic diseases have been summarized in Table $2 .{ }^{45}$

\section{Biosafety of Products and Commercial Processes of Plant} Virus-Based Vectors

It is commonly accepted that despite other organisms are used for the production of pharmaceuticals, human pathogens cannot contaminate plant cells. Also, required materials for plant growth or Agrobacterium culture are not animal derived, therefore, the plant produced recombinant proteins are intrinsically safer than pharmaceuticals produced by animal cells. According to the regulations of Food and Drug Administration (FDA), the validation of such products after protein purification is at least exempted from three stages of purification and decontamination in plant products compared to animal-derived ones. ${ }^{37}$

The manipulation of living organisms potentiated the generation of new sources of plant and animal diseases. Therefore, current technologies for the production of recombinant technologies face numerous problems. This is while, recombinant virus-based vectors for the production of pharmaceutical proteins for human and domestic animal applications possess a suitable level of biosafety. Plant viral vectors are not a threat to human and domestic animals' health and no pathogenicity in mammalian has been reported yet. In some situations, edible plant tissues (expressing recombinant antigen transiently) are used as an alternative to transfer vaccine to the mucous surface (especially oral mucous), removing injection syringe and expenses which also prevents the transmission of blood diseases. Also, the antigen may be protected from destruction and pass the intestine with the help of protective plant materials. It was reported that volunteers who already have immunized by a common rabies vaccine; detectable rates of antibody against rabies virus detected in their blood after eating spinach leaves expressing chimeric rabies virus antigen. ${ }^{6}$ Many factors affecting the immunization of this kind of vaccines and studying the edible vaccine is still in its primitive steps. Expression level or the dosage of antigen should be regulated to be tolerated by the mouth and teeth and to avoid unexpected allergies. ${ }^{65-67}$ Agrobacterium which is used in transient expression systems is a soil-borne, non-pathogenic microorganism for human beings. The interveinal injection of Agrobacterium to mice showed that bacteria could sustain alive 6 days post-injection in the bloodstream but T-DNA had no detectable expression in host tissues. ${ }^{68}$

Another biosafety concern is the presence of endotoxins, polyphenols, and alkaloids in the final product during purification of pharmaceutical proteins from tobacco leaves. Recent reports and technology advances have shown that all unwanted compounds can be removed and there should be no concern about it anymore. The main limitation for the medicinal application of plant-derived recombinant proteins is the difference between $\mathrm{N}$ and O-glycan structure of these proteins with mammalian homologous which may cause an immune response. ${ }^{69,70}$ Recently, different strategies have been developed to overcome this problem including the manipulation of plant glycosylation using RNA interference, simultaneous expression of a specific expression glycotransferase, using especial transgenic lines possessing complex $\mathrm{N}$-glycan lacking immunogenic xylose or fucose epitope and retention of recombinant protein in the endoplasmic reticulum. It is worth mentioning that plant-specific glycosylation in some proteins as vaccines can function as an adjuvant and by improving the immune response, optimizes vaccine efficiency. ${ }^{69}$

\section{Conclusions}

Plant virus-based vectors are used and rapidly developed due to the ease of application and the vast number of them.

Table 2. Current Status of Plant-Derived Therapeutics by Transient Expression System for Epidemic Diseases ${ }^{45}$

\begin{tabular}{lll}
\hline Product & Disease & Plant \\
\hline VLPs & Bluetongue virus (BTV) & Nicotiana benthamiana \\
hE16 & West Nile & Nicotiana benthamiana \\
HA & Influenza virus (H5N1) & Nicotiana benthamiana \\
HA & Influenza virus (H1N1; 2009 pandemic) & Nicotiana benthamiana \\
Hepatitis B antigen (HBsAg) & Hepatitis B & Lettuce and potato \\
Antiviral (griffithsin) & Severe acute respiratory syndrome (SARS) & Nicotiana benthamiana \\
F1-LcrV fusion & Plague & Tomato, Tobacco, and Nicotiana benthamiana \\
B5 & Smallpox & On Market \\
HA (H7; VLP) & Influenza virus (H7N9) & Tobacco and Nicotiana benthamiana \\
HA (VLP) (seasonal; quadrivalent) & Influenza virus & Nicotiana benthamiana \\
\hline
\end{tabular}


Expression level, production of proteins with complex structures and the application of novel hosts are the instances that research and development will speed up around them. The high speed of recombinant production and the inexpensive application of these vectors makes researchers, politicians, and investors to program commercial application of transient expression using virus-based vectors resulting in an everyday increase of validated commercial products produced by transient expression in the world market. Regarding the considerable advancements of the application of viral vectors for the production of animal disease vaccines, the virus-based vectors which are able to target crops for the production of edible vaccines will be likely to be developed more. It seems that in future the strategy of "full virus" for the production of recombinant proteins will be limited to research use only and will be gradually eliminated. An increasing demand for high-quality recombinant proteins is inevitable; therefore, biological systems which are able to produce these proteins cost-effectively should be developed. According to scientific references, plant expression systems using virus-based vectors have the highest potential for a large and commercial scale production. ${ }^{71}$ Lack of environmental concerns and crop contamination using this technology has offered confidence and composure for researchers. On the whole, there is an open horizon ahead of transient expression technology using virus-based vectors and it is thought that in many cases it will replace other platforms and hosts for the production of recombinant protein.

\section{Authors' Contributions}

ZN and GK contributed equally to the writing of the article and drawings, SJD has designed the paper structure and contributed to the writing, editing and revising the article and $\mathrm{HO}$ contributed to the writing of the article.

\section{Conflict of Interest Disclosures}

The authors declare they have no conflicts of interest.

\section{Ethical Approva}

Not applicable.

\section{References}

1. Ferrer-Miralles N, Saccardo P, Corchero JL, Xu Z, García-Fruitós E. General introduction: recombinant protein production and purification of insoluble proteins. In: García-Fruitós E, eds. Insoluble Proteins. New York: Humana Press; 2015:1-24.

2. Clark DP, Pazdernik NJ. Biotechnology. Oxford: Newnes; 2015.

3. Gleba Y, Klimyuk V, Marillonnet S. Viral vectors for the expression of proteins in plants. Curr Opin Biotech. 2007;18(2):134-141. doi:10.1016/j.copbio.2007.03.002.

4. Yang L, Wang $\mathrm{H}$, Liu J, et al. A simple and effective system for foreign gene expression in plants via root absorption of agrobacterial suspension. J Biotechnol. 2008;134(3-4):320-324. doi:10.1016/j.jbiotec.2008.01.019.

5. Thuenemann EC, Lenzi P, Love AJ, et al. The use of transient expression systems for the rapid production of virus-like particles in plants. Curr Pharm Design. 2013;19(31):5564-5573. doi:10.21 74/1381612811319310011.

6. Cunningham C, Porter AJ. Recombinant proteins from plants: production and isolation of clinically useful compounds. New Jersey: Springer Science \& Business Media; 1998.

7. Davarpanah SJ, Ahn JW, Ko SM, et al. Stable expression of a fungal laccase protein using transplastomic tobacco. Plant Biotechnol
Rep. 2012;6(4):305-312. doi:10.1007/s11816-012-0225-4.

8. Ofoghi H, Yavari F, Nazarain F. Tissue specific expression of human calcitonin gene in potato tubers by an organ specific promoter. Iran J Biotechnol 2012;10:79-86.

9. Kordbacheh F, Ofoghi H, Akbarzadeh A, Jafari M, Salmanian A-H. High level expression and chloroplast targeting of human calcitonin (hCT) in transgenic tobacco plants. Transgenic Plant J. 2000;5(1):57-61.

10. Hamideh O, Fatemeh GP. Targeted expression of human calcitonin gene to potato tuber. J Biotechnol. 2008;136(Suppl):S144. doi:10.1016/j.jbiotec.2008.07.307.

11. Shafaghi $M$, Maktoobian $S$, Rasouli $R$, Howaizi $N$, Ofoghi $H$, Ehsani P. Transient expression of biologically active anti-rabies virus monoclonal antibody in tobacco leaves. Iran Journal Biotechnol. 2018;16(1):1-10. doi:10.21859/ijb.1774.

12. Fischer R, Emans N. Molecular farming of pharmaceutical proteins. Transgenic Res. 2000;9(4-5):279-299.

13. Gleba Y, Klimyuk V, Marillonnet S. Magnifection-a new platform for expressing recombinant vaccines in plants. Vaccine. 2005;23(17):2042-2048. doi:10.1016/j.vaccine.2005.01.006.

14. Fan Y, Li W, Wang J, et al. Efficient production of human acidic fibroblast growth factor in pea (Pisum sativum L.) plants by agroinfection of germinated seeds. BMC Biotechnol. 2011;11(1):45. doi:10.1186/1472-6750-11-45.

15. Davarpanah SJ, Jung SH, Kim YJ, et al. Stable plastid transformation in Nicotiana benthamiana. J Plant Biol. 2009;52(3.244-50:(. doi:10.1007/s12374-009-9023-0.

16. Ghanbari Motlagh M, Amini-Bayat Z, Ofoghi H. Investigation of an optimized context for the expression of GFP as a reporter gene in Chlamydomonas reinhardtii. Biomacromolecular J. 2016;2(2):135-142.

17. Kusnadi AR, Nikolov ZL, Howard JA. Production of recombinant proteins in transgenic plants: practical considerations. Biotechnol Bioeng. 1997;56(5):473-484. doi:10.1002/(sici)10970290(19971205)56:5\%3C473::aid-bit1\%3E3.0.co;2-f.

18. Zupan JR, Zambryski P. Transfer of T-DNA from Agrobacterium to the plant cell. Plant Physiology. 1995;107(4):1041. doi:10.1104/ pp.107.4.1041.

19. Hellens RP, Allan AC, Friel EN, et al. Transient expression vectors for functional genomics, quantification of promoter activity and RNA silencing in plants. Plant Methods. 2005;1(1):13.

20. Mamiatis T, Fritsch E, Sambrook J, Engel J. Molecular cloning-A laboratory manual. New York: Cold Spring Harbor Laboratory; 1982.

21. Tzfira T, Citovsky V. Partners-in-infection: host proteins involved in the transformation of plant cells by Agrobacterium. Trends Cell Biol. 2002;12(3):121-129. doi:10.1016/s0962-8924(01)02229-2.

22. Samuels TD, Ju HJ, Ye CM, Motes CM, Blancaflor EB, VerchotLubicz J. Subcellular targeting and interactions among the Potato virus X TGB proteins. Virology. 2007;367(2):375-389. doi:10.1016/j.virol.2007.05.022.

23. Negrouk V, Eisner G, Lee H-i, Han K, Taylor D, Wong HC. Highly efficient transient expression of functional recombinant antibodies in lettuce. Plant Sci. 2005;169(2):433-438. doi:10.1016/j. plantsci.2005.03.031.

24. Prokhnevsky A, Mamedov T, Leffet B, Rahimova R, Ghosh A, Mett $V$, et al. Development of a single-replicon miniBYV vector for co-expression of heterologous proteins. Molecular Biotechnol. 2015;57(2):101-110. doi:10.1007/s12033-014-9806-5.

25. Dinesh-Kumar S, Anandalakshmi R, Marathe R, Schiff M, Liu Y. Virus-induced gene silencing. In: Grotewold E, eds. Plant Functional Genomics. Totowa: Springer; 2003:287-293.

26. Kapila J, De Rycke R, Van Montagu M, Angenon G. An Agrobacterium-mediated transient gene expression system for intact leaves. Plant Sci. 1997;122(1):101-108. doi:10.1016/s01689452(97)04651-7.

27. Marillonnet S, Thoeringer C, Kandzia R, Klimyuk V, Gleba Y. Systemic Agrobacterium tumefaciens-mediated transfection of 
viral replicons for efficient transient expression in plants. Nat Biotechnol. 2005;23(6):718. doi:10.1038/nbt1094.

28. van Regenmortel MH, Mahy BW. Desk Encyclopedia of Plant and Fungal Virology. Cambridge: Academic Press; 2009.

29. Haynes JR, Cunningham J, Von Seefried A, Lennick M, Garvin RT, Shen $\mathrm{SH}$. Development of a genetically-engineered, candidate polio vaccine employing the self-assembling properties of the tobacco mosaic virus coat protein. Nat Biotechnol. 1986;4(7):637. doi:10.1038/nbt0786-637

30. Fahad S, Khan FA, Pandupuspitasari NS, et al. Recent developments in therapeutic protein expression technologies in plants. Biotechnol Lett.2015;37(2):265-279.doi:10.1007/s10529-014-1699-7.

31. Scholthof HB, Scholthof K-BG, Jackson AO. Plant virus gene vectors for transient expression of foreign proteins in plants. Rev Phytopathol. 1996;34(1):299-323. doi:10.1146/annurev. phyto.34.1.299

32. Azhakanandam K, Weissinger SM, Nicholson JS, Qu R, Weissinger AK. Amplicon-plus targeting technology (APTT) for rapid production of a highly unstable vaccine protein in tobacco plants. Plant Mol Biol. 2007;63(3):393-404. doi:10.1007/s11103-0079168-5.

33. Kohl T, Hitzeroth I, Stewart D, et al. Plant-produced cottontail rabbit papillomavirus $\mathrm{L} 1$ protein protects against tumor challenge: a proof-of-concept study. Clin Vaccine Immunol. 2006;13(8):845853. doi:10.1128/cvi.00072-06.

34. Varsani A, Williamson A-L, Stewart D, Rybicki EP. Transient expression of Human papillomavirus type 16 L1 protein in Nicotiana benthamiana using an infectious tobamovirus vector. Virus Res. 2006;120(1-2):91-96. doi:10.1016/j.virusres.2006.01.022.

35. Avesani L, Marconi G, Morandini F, et al. Stability of Potato virus $X$ expression vectors is related to insert size: implications for replication models and risk assessment. Transgenic Res. 2007;16(5):587-597. doi:10.1007/s11248-006-9051-1.

36. Mett V, Farrance CE, Green BJ, Yusibov V. Plants as biofactories. Biologicals. 2008;36(6):354-358. doi:10.1016/j. biologicals.2008.09.001

37. Gleba YY, Tusé D, Giritch A. Plant viral vectors for delivery by Agrobacterium. In: Palmer K, Gleba Y, eds. Plant Viral Vectors. Berlin: Springer; 2013:155-192.

38. Gleba Y, Marillonnet S, Klimyuk V. Engineering viral expression vectors for plants: the 'full virus' and the 'deconstructed virus' strategies. Curr Opin Plant Biol. 2004;7(2):182-188. doi:10.1016/j. pbi.2004.01.003.

39. Pogue GP, Lindbo JA, Garger SJ, Fitzmaurice WP. Making an ally from an enemy: plant virology and the new agriculture. Annual Rev Phytopathol. 2002;40(1):45-74.

40. Barker RF1, Idler KB, Thompson DV, KempJD. Nucleotide sequence of the T-DNA region from theA grobacterium tumefaciens octopine Ti plasmid pTi15955. Send to Plant Mol Biol. 1983 Nov;2(6):33550.doi:10.1007/BF01578595.

41. Gleba $Y$, Klimyuk $V$, Marillonnet S. Magnifection-a new platform for expressing recombinant vaccines in plants. Vaccine. 2005;23(17-18):2042-2048. doi:10.1016/j.vaccine.2005.01.006

42. Salazar-González JA, Rosales-Mendoza S, Bañuelos-Hernández B. Viral vector-based expression strategies. In: Rosales-Mendoza S, eds. Genetically Engineered Plants as a Source of Vaccines against Wide Spread Diseases. New York: Springer; 2014:43-60. doi:10.1007/978-1-4939-0850-9 3.

43. Hefferon KL. Plant virus expression vectors set the stage as production platforms for biopharmaceutical proteins. Virology. 2012;433(1):1-6. doi:10.1007/978-1-4939-0850-9_3.

44. Bustamante PI, Hull R. Plant virus gene expression strategies. Electron J Biotechno. 1998;1(2):13-24. doi:10.2225/vol1-issue2fulltext-3.

45. Sharma R, Sathishkumar R. Rapid production of therapeutic proteins using plant system. Defence Life Sci J. 2017;2:95-102. doi:10.14429/dlsj.2.11372.

46. Klimyuk V, Marillonnet S, Knäblein J, McCaman M, Gleba
Y. Production of recombinant proteins in plants. In: Knäblein J, eds. Modern Biopharmaceuticals: Design, Development and Optimization. New Jersey: Wiley; 2005:893-917. doi:10.1002/9783527620982.ch36.

47. Menassa R, Ahmad A, Joensuu JJ. Transient expression using agroinfiltration and its applications in molecular farming. In: Wang A, Ma S, eds. Molecular farming in plants: recent advances and future prospects. Dordrecht: Springer; 2012:183-198. doi:10.1007/978-94-007-2217-0_9.

48. Vézina LP, Faye L, Lerouge $\mathrm{P}$, et al. Transient co-expression for fast and high-yield production of antibodies with human-like $\mathrm{N}$-glycans in plants. Plant Biotechnol J. 20099;7(5.442-55:(. doi:10.1111/j.1467-7652.2009.00414.x.

49. Hitzeroth II, van Zyl AR. Transient expression of viral proteins in plants using Agrobacterium tumefaciens. In: Thomas S, eds. Vaccine Design: Methods and Protocols, Volume 2: Vaccines for Veterinary Diseases. New York: Humana Press; 2016:581-595. doi:10.1007/978-1-4939-3389-1_38.

50. Hellens R, Mullineaux $\mathrm{P}, \mathrm{Klee} \mathrm{H}$. Technical focus: a guide to Agrobacterium binary Ti vectors. Trends Plant Sci. 2000;5(10):446451. doi:10.1016/s1360-1385(00)01740-4.

51. Takeda A, Sugiyama K, Nagano $\mathrm{H}$, et al. Identification of a novel RNA silencing suppressor, NSs protein of Tomato spotted wilt virus. FEBS Lett. 2002;532(1-2):75-79. doi:10.1016/s00145793(02)03632-3.

52. Gils M, Kandzia R, Marillonnet S, Klimyuk V, Gleba Y. High-yield production of authentic human growth hormone using a plant virus-based expression system. Plant Biotechnol J. 2005;3(6):613620. doi:10.1111/j.1467-7652.2005.00154.x.

53. Santi L, Giritch A, Roy CJ, et al. Protection conferred by recombinant Yersinia pestis antigens produced by a rapid and highly scalable plant expression system. P Natl Acad Sci USA. 2006;103(4):861866. doi:10.1073/pnas.0510014103.

54. Dorokhov YL, Sheveleva AA, Frolova OY, et al. Superexpression of tuberculosis antigens in plant leaves. Tuberculosis. 2007;87(3):218224.doi:10.1016/j.tube.2006.10.001

55. Karasev AV, Foulke S, Wellens C, et al. Plant based HIV-1 vaccine candidate: Tat protein produced in spinach. Vaccine. 2005;23(15):1875-1880. doi:10.1016/j.vaccine.2004.11.021.

56. Komarova TV, Baschieri S, Donini M, Marusic C, Benvenuto E, Dorokhov YL. Transient expression systems for plant-derived biopharmaceuticals. Expert Rev Vaccines. 2010;9(8):859-876. doi:10.1586/erv.10.85.

57. Saejung W, Fujiyama K, Takasaki T, et al. Production of dengue 2 envelope domain III in plant using TMV-based vector system. Vaccine. 2007;25(36):6646-6654. doi:10.1016/j. vaccine.2007.06.029.

58. Komarova TV, Baschieri S, Donini M, Marusic C, Benvenuto E, Dorokhov YL. Transient expression systems for plant-derived biopharmaceuticals. Expert Rev Vaccines. 2010;9:859-576. doi:10.1586/erv.10.85

59. Giritch A, Marillonnet S, Engler C, et al. Rapid high-yield expression of full-size IgG antibodies in plants coinfected with noncompeting viral vectors. P Natl A Sci. 2006;103(40):1470114706. doi:10.1073/pnas.0606631103.

60. Huang Z, LePore K, Elkin G, Thanavala Y, Mason HS. High-yield rapid production of hepatitis $B$ surface antigen in plant leaf by a viral expression system. Plant Biotechnol J. 2008;6(2):202-209. doi:10.1111/j.1467-7652.2007.00316.x.

61. D'Aoust MA, Couture MMJ, Charland N, et al. The production of hemagglutinin-based virus-like particles in plants: a rapid, efficient and safe response to pandemic influenza. Plant Biotechnol J. 2010;8(5):607-619. doi:10.1111/j.1467-7652.2009.00496.x.

62. Pogue GP, Vojdani F, Palmer KE, et al. Production of pharmaceuticalgrade recombinant aprotinin and a monoclonal antibody product using plant-based transient expression systems. Plant Biotechnol J. 2010;8(5):638-654.doi:10.1111/j.1467-7652.2009.00495.x.

63. Čeřovská N, Pečenková T, Moravec T, Velemínský J. Transient 
expression of heterologous model gene in plants using Potato virusX-based vector. Plant cell, tissue and organ cultur 2004;79(2):147-152. doi:10.1007/s11240-004-0654-z.

64. Yusibov V, Hooper D, Spitsin S, et al. Expression in plants and immunogenicity of plant virus-based experimental rabies vaccine. Vaccine. 2002;20(25-26):3155-3164. doi:10.1016/s0264410x(02)00260-8.

65. Smart V, Foster PS, Rothenberg ME, Higgins T, Hogan S. A plantbased allergy vaccine suppresses experimental asthma via an IFN- $\gamma$ and CD4+ CD45RBlow T cell-dependent mechanism. J Immunol. 2003;171(4):2116-2126. doi:10.4049/jimmunol.171.4.2116.

66. Tacket C. Plant-based oral vaccines: results of human trials . In: Karasev AV, eds. Plant-produced Microbial Vaccines. Berlin: Springer; 2009:103-117. doi:10.1007/978-3-540-70868-1_6.

67. Takagi H, Hiroi T, Yang L, Tada Y, Yuki Y, Takamura K, et al. A ricebased edible vaccine expressing multiple $\mathrm{T}$ cell epitopes induces oral tolerance for inhibition of Th2-mediated IgE responses. $\mathrm{P}$ Natl Acad Sci USA. 2005;102(48):17525-17530. doi:10.1073/ pnas.0503428102.

68. Petrunia IV, Frolova OY, Komarova TV, Kiselev SL, Citovsky V, Dorokhov YL. Agrobacterium tumefaciens-induced bacteraemia does not lead to reporter gene expression in mouse organs. PloS One. 2008;3(6):e2352. doi:10.1371/journal.pone.0002352.

69. Gomord V, Fitchette AC, Menu-Bouaouiche L, Saint-Jore-Dupas C, Plasson C, Michaud D, et al. Plant-specific glycosylation patterns in the context of therapeutic protein production. Plant biotechnol J. 2010;8(5):564-587. doi:10.1111/j.1467-7652.2009.00497.x.

70. Lombardi R, Villani ME, Di Carli M, Brunetti P, Benvenuto $E$, Donini M. Optimisation of the purification process of a tumour-targeting antibody produced in $\mathrm{N}$. benthamiana using vacuum-agroinfiltration. Transgenic Res. 2010;19(6):1083-1097. doi:10.1007/s11248-010-9382-9.

71. Lico C, Chen Q, Santi L. Viral vectors for production of recombinant proteins in plants. J Cell Physiol. 2008;216(2):366377. doi:10.1002/jcp.21423. 